\title{
Knowledge Sharing and the Improvement of Service Delivery in an Academic Library
}

\author{
Tšeole Emmanuel Tahleho, National University of Lesotho, Lesotho \\ Patrick Ngulube, University of South Africa, South Africa \\ iD https://orcid.org/0000-0002-7676-3931
}

\begin{abstract}
Knowledge can play an important role in ascertaining an organization's competitive edge if the knowledge of employees is nurtured and utilized as an asset with a potential to improve service delivery. The study focused on knowledge sharing at the Thomas Mofolo Library in Lesotho to determine if knowledge sharing was being used to improve service delivery at the library. A case study design that triangulated interviews and questionnaires was used in this study. Quantitative data was processed using software packages. Data from the interviews was analyzed through content analysis based on the objectives of the study. This study established that staff recognized the need to share knowledge. However, knowledge sharing occurred on an ad hoc basis. There was a limited use of technology-based and human-based mechanisms of sharing knowledge. The study suggests practical knowledge-sharing practices that may contribute to improved service delivery in a library setup. As a case study, the study may also contribute to the development of theory about the phenomenon.
\end{abstract}

\section{KEYWORDS}

Academic Library, Knowledge Circulation, Knowledge Loss, Knowledge Management, Thomas Mofolo Library

\section{INTRODUCTION AND BACKGROUND TO THE STUDY}

Traditionally, academic libraries are established with the aim to collect, process, disseminate, store and utilize information to provide a service to their research community and advance the wellbeing of mankind (Rajurkur, 2011; Wen, 2005). As service providers, academic libraries are established for the provision of related information resources and quality services in order to satisfy their users' information needs (Andeniran, 2011). Meeting the information needs of clients is no longer a choice for libraries, but an obligation that libraries should achieve in the knowledge-based economy.

However, due to political, economic, social and technological (PEST) factors, including the demands of the knowledge economy, the environment in which academic libraries function today is shifting and unstable. The resultant instability has compelled academic libraries to deal with issues of reduced budgets against increased demand from the faculty and the student community to respond to the diverse challenges of the knowledge economy (Rajurkur, 2011). Nonetheless, academic libraries still have to deliver on their mandate and maneuver the rocky terrain by reengineering, repositioning and reinventing themselves to deal with the ever-changing situation. If they do not adapt, they are likely to cease to be visible and valuable. 
One of the strategies that academic libraries can use, not only to survive but also to grow and be sustainable in the knowledge era, is to improve the quality of services and products provided to users who are at the center of their existence. Their success partly depends on their ability to utilize information and the knowledge of staff to better serve the needs of the academic community. Maponya (2004) and Rao (2018) identified knowledge sharing as one of the feasible strategies which libraries may employ to improve their services in the knowledge economy by exploiting the often-disregarded capabilities of their employees. Lessons learned from past failures and successes for its members can be shared to achieve the vision of the organization and improve the delivery of services.

Knowledge sharing contributes to improving the quality of service delivery of an organization. The following questions need to be asked if one is to determine the existence of knowledge sharing in the context of academic libraries: (i) Are academic librarians encouraged to share knowledge?; (ii) Are the skills and competencies in the academic library identified and shared?; (iii) How is the knowledge shared?; and (iv) Does the working environment support a knowledge-sharing culture? (Maponya, 2004).

Given the challenges posed by the PEST environment, knowledge sharing holds promise as a tool that can be used to strengthen the knowledge and skills levels of practitioners at a lower cost in support of service delivery. The value of knowledge increases when it is shared (Dube \& Ngulube, 2012). Smith and McKeen (2009) underscored the fact that the value of knowledge increases when it has a key purpose and focuses on missions, core values and strategic priorities.

\section{CONTEXT OF THE STUDY}

The origins of the National University of Lesotho (NUL) can be traced to the establishment of Pius XII University of Basutoland, Bechuanaland Protectorate and Swaziland in 1964. It was renamed the University of Botswana, Lesotho and Swaziland in 1966 at the end of colonial rule in the three countries (Hundie, 2001).

NUL was established as a separate entity in 1967. NUL is still located in Roma, Maseru in the capital of the kingdom of Lesotho and uses the same premises as its predecessors. The institution seeks to advance human development and to respond to national and regional needs through knowledge creation, dissemination as well as community engagement, employing technologically innovative strategies (National University of Lesotho strategic plan 2015-2020, 2016). All the activities partly depend on the services provided by the library.

\section{LITERATURE REVIEW ON KNOWLEDGE SHARING AND ITS ROLE IN IMPROVING SERVICE DELIVERY}

It is apparent that expertise exists in people. However, much of the knowledge is implicit rather than explicit in nature and this makes it complicated to transfer. Jeung, Yoon and Choi (2017) defined knowledge sharing as the process through which knowledge, information, skills and expertise are transferred and shared amid people, friends, families, organizations and societies. Knowledge sharing may also be defined as the desire of an organisational employee to provide other employees with the knowledge that he or she has created or acquired (Castaneda \& Toulson, 2021). Oyemomi, Liu and Neaga (2015) contended that the importance of knowledge sharing is so highly rated to an extent that some researchers have concluded that KM exists in order to support knowledge sharing. They argued further that "organization that supports information sharing and knowledge production among its staff members can lead to effective and efficient processes and improve organizational performance"

Dube and Ngulube (2012) as well as Castaneda and Toulson (2021) argued that knowledge sharing could give an organization a competitive advantage. The people engaged in the process of knowledge sharing may enhance their performance through exploiting their collective intellectual capital (Dube \& Ngulube, 2012; Castaneda \& Toulson, 2021). Similarly, Brčić and Mihelič (2015) 
posited that knowledge is regarded as the most important resource for the economy's and a company's principal source of production and value. They caution however, that in order to benefit from it, the knowledge has to be shared among employees.

Jantz (2001) and Marouf (2017) opined that by using and sharing knowledge, libraries will improve their services. Nevertheless, given the library's dwindling budgets, academic libraries are compelled to increase their operational efficiency in order to meet the challenge. One such management tool that may be employed to help in this regard is the knowledge management process of knowledge sharing (Wen, 2005; Marouf, 2017). Furthermore, Burnette (2017) remarked that a profound comprehension of circumstances and triggers of knowledge exchanges between librarians, and the types of knowledge they share, contributes to the development of effective processes and conditions for capturing critical knowledge. If knowledge sharing is practiced in libraries, personal knowledge may be turned into corporate knowledge that can be widely shared throughout the library and applied appropriately. Knowledge sharing enables the organization to assimilate both internal and external knowledge, detect opportunities and obtain more advantageous positions linked to the organisation's innovation and performance (Lekhawipat, Wei \& Lin, 2018; Ta \& Zyngier, 2018; Todorova \& Mills, 2018). Asogwa (2012) explained that knowledge-sharing practices in libraries become important in harnessing the wealth, wisdom, expertise and experiences the retiring employees.

Knowledge sharing may be practiced through the adoption of human and technology-based strategies. However, Davenport, De Long and Beers (1998) as well as Zenk, Hynek, Edelmann, Virkar, Parycek and Steiner (2021) cautioned that there is no amount of technology, knowledge content or even good project management practices would make knowledge sharing achievable if the cultural soil is not fertile. Knowledge sharing may be achieved through the use of non-technological strategies including mentoring, exit interviews, communities of practice (CoPs), job shadowing, storytelling and job rotation (Malinski, 2002; Colon-Aguirre, 2015; Kim, 2015; Daland, 2016). This can be partly be achieved through brainstorming, open discussions and provision of suitable or conducive grounds for creativity, sharing of ideas, organizing workshops, conferences, mentoring, web archiving, digitizing, identification and collectively addressing problems and finding solutions (Asogwa, 2012).

Knowledge sharing may also be successfully achieved through the usage of enabling technologies including email, intranet, data mining, data warehousing, social media mechanisms (web 2.0) and other collaborative technologies (Bhojaraju, 2005; Jain, 2013). Hosseini and Hashempour (2012) and Castanada and Toulson (2021) explained that the advancement in modern information tools has allowed knowledge workers to collaborate and participate more and share knowledge by means of web 2.0 tools. These tools have enabled information professionals to share their knowledge with their colleagues in order to meet the needs of their users effectively and efficiently (Hosseini \& Hashempour, 2012). For instance, Intranets are becoming a common feature in many organizations (Averweg, 2008). With the increasing use of a technology infrastructure such as the intranet in organizations, there is a continuous challenge for employees to take advantage of the technology to contribute their knowledge willingly and to make use of knowledge sharing among employees. Emails and blogs alike can be very powerful tools for transferring tacit knowledge in organizations with the necessary technological infrastructure. Blogs are easy to create, maintain and use and thus reduce the technical skills required from the users to exploit its features.

Knowledge sharing may occur if some mechanisms are in existence. Knowledge retention mechanisms include trust, communication, leadership, management support, and organizational structure and reward systems (Islam, Ahmed, Hasan, \& Ahmed, 2011). Members of an organization need to trust one another to be honest, capable and committed to join arms in order to create and share knowledge (Ngulube, 2005; Burnette, 2017; Gerbin \&Dornovsek, 2020). According to Tan Nya Ling (2011), despite the fact that knowledge sharing is important, workers may be still skeptical of those they have to share knowledge with. A lack of trust among employees may be inimical to knowledge sharing in an organization (Ngulube, 2005, Burnette, 2017; Gerbin \& Drnovsek, 2020). Communication contributes to knowledge sharing as it is related to trust in different inter-organizational 
relationships. Davenport \& Prusak (1997), Islam et al, (2011) as well as Sanford, Schwartz and Khan 2020) stated that organizations that encourage knowledge sharing and knowledge integration into the organization create a floor for open discussion and debate and this motivates individuals at various levels to freely give their opinions and views on different issues.

Furthermore, the provision of support by the management has been closely linked with employees' perceptions of a knowledge-sharing culture and willingness to share knowledge (AlShamsi \& Ajmal, 2018). Top management support affects both the level and quality of knowledge sharing by inñuencing employee commitment to knowledge management (AlShamsi \& Ajmal, 2018). The aptitude of management should be supported by a reward system. The absence of incentives has been suggested to be a main obstacle to knowledge sharing across cultures (Arzi, Rabanifard, Nassajtarshizi, \& Omran, 2013; Wang and Noe, 2010; Zenk et al.,2021). Incentives, including recognition and rewards, have been suggested as interventions to ease knowledge sharing and help build a supportive culture (Wang \& Noe, 2010). The structure of the organization also plays a role in knowledge sharing. Organizational demographics, especially large size and formal status differentials, have a negative influence on knowledge sharing (Ramirez, 2007). Tagliaventi and Mattarelli (2006), Wang and Noe (2010) and Alawamleh and Kloub, (2013) opined that a functionally segmented organization is likely to impede knowledge sharing across functions and communities of practice.

A number of obstacles to knowledge sharing are well documented. An understanding of the obstacles to knowledge sharing in organizations is vital in order to explore strategies to encourage knowledge sharing. Information or knowledge is power; inequalities in status and perceived lack of job security are potential barriers to knowledge sharing (Ramirez, 2007; Riege, 2005; Mat Nor, Mat Khairi, Rosnan, Maskun, \& Johar, 2020). In the old school of thinking where profitability was reflected by an organization's output, knowledge hoarding rather than sharing was believed to benefit career advancement. A lack of trust among employees may also be detrimental to knowledge sharing in an organization (Ngulube, 2005; Raman, Mannan, Hossain, Zaman and Hassan, 2018; Ta \& Zyngier, 2018; Mat Nor, Mat Khairi, Rosnan, Maskun, \& Johar, 2020).

\section{STATEMENT OF THE PROBLEM AND RESEARCH QUESTIONS}

Knowledge sharing plays an important role in organizational processes because it helps organizations to transfer new ideas or solutions (Tan Nya Ling, 2011). Furthermore, the implications of knowledge loss are dire, and include attrition of organizational memory, knowledge gap, lack of continuity and the economics of knowledge loss. Knowledge sharing implies that all the pockets of excellence among the employees are pulled together to improve the services to the clientele.

Mavodza and Ngulube (2011) noted that some academic libraries in the developed world have significantly developed because of the adoption and use of knowledge management (KM) principles and practices in the provision of library services. However, little is known about how information professionals at TML practice knowledge management activities such as knowledge sharing. Librarians at TML have different sets of skills which, if combined, may improve service delivery. The study was guided by the following research questions:

1. What is the understanding of knowledge sharing at TML?

2. What are the perceptions of librarians at TML about sharing knowledge?

3. What tools are used for sharing knowledge?

4. What are the critical success factors for sharing knowledge?

5. What obstacles are related to knowledge sharing? 


\section{METHODOLOGY}

Both qualitative and quantitative research methods were employed within a case study design in order to facilitate multiple methods of data collection. Triangulation of data sources enhances the validity of research results. Data was collected by means of questionnaires and interviews. Questionnaires were administered to all librarians and purposive sampling was used to determine the five interview participants at senior management level.

Out of the 25 questionnaires administered, 15 were returned, providing a response rate of $60 \%$. The data collected by means of questionnaires was processed using Microsoft Access and analyzed using the Statistical Package for Social Science (SPSS) software (Version 17). The results of analysis were exported into Microsoft Excel for visual presentation and reporting of the results. The data from the interview sessions was analyzed manually by content analysis, using the notes that were taken by the researcher from the respondents during the interview sessions. A descriptive account of the findings is presented and discussed below using references to the reviewed literature that framed this study.

\section{FINDINGS AND DISCUSSIONS}

This section presents the study findings as informed by the objectives of the study.

\section{The Understanding of Knowledge Sharing at TML}

To find out if TML staff understood the concept of knowledge sharing, respondents were asked about their general opinion on knowledge sharing. The results show that 9 (60\%) out of 15 respondents thought knowledge sharing was important to service delivery. This is in line with what Maponya (2004) noted when she asserted that knowledge sharing is one of the viable means in which academic libraries could improve their services in the age of knowledge workers. On the other hand, another six $(40 \%)$ respondents were of the opinion that knowledge sharing provided advantages to organizations. This also corresponds to the findings of Kamal, Manjit and Gurvinder (2007), which demonstrated the role of knowledge in driving the economy in a knowledge economy landscape.

On further soliciting respondents' views on knowledge sharing, respondents were asked if they thought knowledge sharing may help other TML staff to solve problems. A total of 14 (93.3\%) respondents were of the opinion that knowledge sharing may assist other TML staff to solve problems, compared to $1(6.7 \%)$ respondent who did not answer this question. The fact that the majority of respondents are of the view that knowledge sharing may help them solve problems at the library is in line with what Christensen (2007) alluded to when he stated that if knowledge is not shared, then there is a risk of reinventing the wheel when dealing with problems. In a library environment, this may happen when, for example, services providers in the evening shift make the same mistakes that service providers in the day shift have already made.

The respondents who thought that knowledge sharing may assist other TML staff in solving problems were requested to further explain how knowledge sharing may assist TML staff in solving their problems. Table 1 below summarizes some of their responses.

Although some of the respondents understood the advantages of knowledge sharing, it was formalized according to eight $(53.3 \%)$ respondents. This was contrary to suggestions in the literature (Maponya, 2004) that revealed that knowledge sharing in academic libraries happened in an ad hoc manner, a great deal of knowledge sharing was utterly uncoordinated, and any sharing of knowledge was on an informal basis and usually based on conversations.

On the importance of making knowledge sharing formal at TML, all the respondents indicated it is important to formalize knowledge sharing. They even suggested to the researchers that the introduction of a knowledge management position in the Library to deal with all the knowledge management issues may go a long way in addressing knowledge loss at TML. Of particular importance to the formalization of knowledge management is the following responses from two respondents. 
Table 1. How knowledge sharing may assist TML staff

\begin{tabular}{|l|l|}
\hline Explanations & Number of respondents \\
\hline $\begin{array}{l}\text { Enhancing, supplementing or building up one's own knowledge with that of } \\
\text { others; providing synergy on what is lacking or on what is already existing; } \\
\text { allowing diffusion at various levels }\end{array}$ & 1 \\
\hline Staff will be able to work efficiently and learn from others & 1 \\
\hline By copying from others who have experience & 1 \\
\hline $\begin{array}{l}\text { By sharing activities and knowledge through which skills and expertise could be } \\
\text { exchanged among organizations and co-workers }\end{array}$ & 1 \\
\hline $\begin{array}{l}\text { Sharing something that has to be known by all at TML to ensure that serving } \\
\text { TML users run smoothly }\end{array}$ & 1 \\
\hline
\end{tabular}

Respondent 1: I think one of the reasons why knowledge sharing is not formalized at TML is maybe it was not emphasized even during our formal training period at different universities. I think it is only lately that it is being emphasized.

Respondent 2: I think knowledge sharing is not formalized because no one really knows and understands it.

Even if the respondents understand the need to share knowledge there is a need to formalize the process through establishing the requisite structures. The fact that only eight reported that knowledge sharing was formalized is revealing. Our suspicion that knowledge was shared on an ad hoc basis was corroborated by interview data from senior management staff as the two responses captured above illustrate.

\section{Knowledge Sharing Among Librarians}

The researchers further sought to find out the extent to which the respondents shared knowledge on work-related matters. The largest number of respondents, 11 (73.3\%), agreed that they shared knowledge, with 5 (33.3\%) strongly agreeing. A small number of respondents, two (13.3\%), disagreed, which was at equilibrium with the respondents who were not sure. The fact that the majority of the respondents agreed that librarians shared information and knowledge about work issues is indicative that knowledge was shared, albeit in an informal way. According to Ramirez (2007) and Ta and Zyngier (2018, knowledge sharing enables employees to share their insights and experiences in order to allow faster and more cost-effective project completions. Employees can draw upon the experiences of others in their pursuit of finding solutions to problems. In turn this may lead to efficient service delivery as expertise would be shared to achieve a common goal.

\section{Knowledge-Sharing Tools (Technology-Based)}

One of the study objectives was to identify tools for knowledge sharing.

\section{Technologies in use at TML}

The researchers asked if TML staff were using various technology-based knowledge-sharing tools, and multiple responses to the question item were possible. Figure 1 summarizes their responses.

Despite the fact that they did not use these technology-based platforms to share knowledge as revealed in their responses, it is important that they exist. When fully exploited, these technologies may be the enablers of knowledge sharing. The application of information technologies enlarges the scope of knowledge acquisition, which is a key process in managing knowledge (Shanhong, 2000). Ramirez (2007) concurred with Shanhong (2000) and stated that information technology makes 


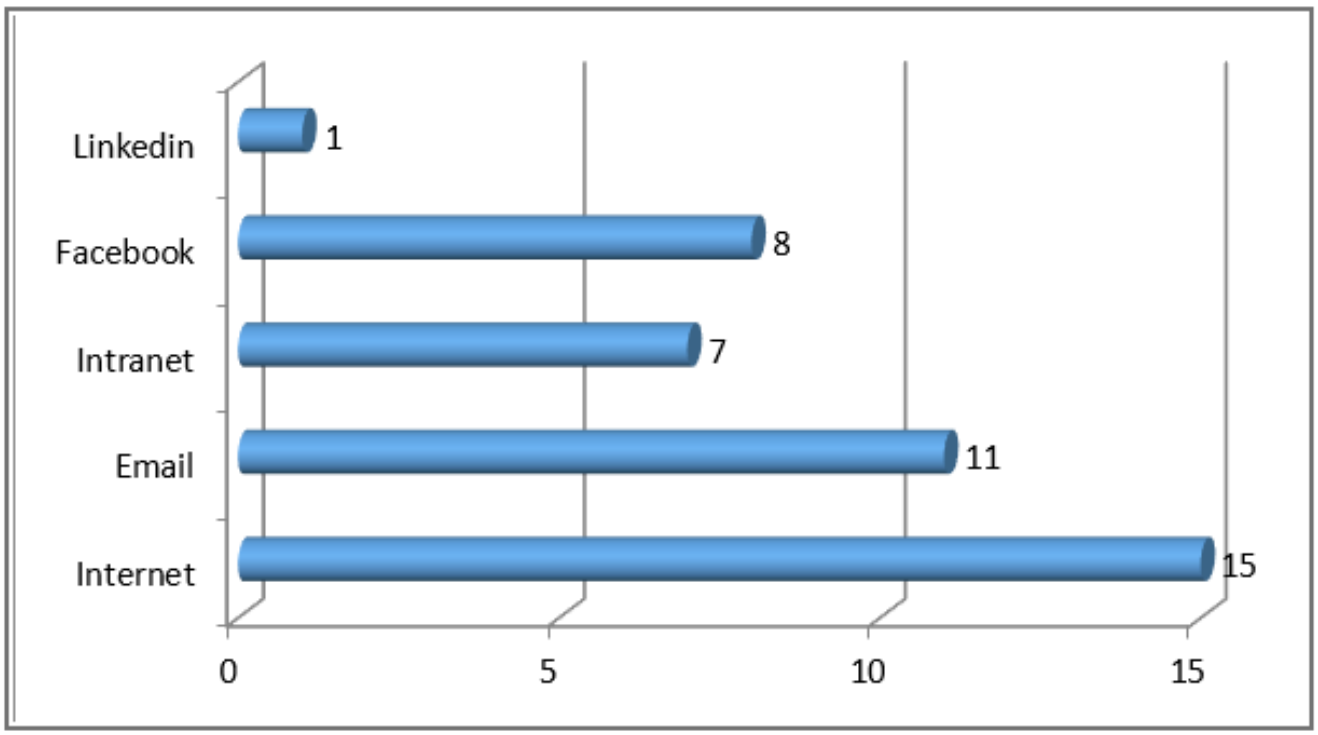

probable the connections that enable knowledge sharing, although it does not motivate staff to share their knowledge. Given the importance of these technologies and the fact that TML already has them, using these technologies may go a long way in harnessing what they already have in relation to knowledge sharing.

\section{Knowledge-Sharing Tools (Human-Based)}

The question item on human-based knowledge-sharing tools sought to find out those that were in use at TML. From the categories that included communities of practice (CoPs), mentorship programs, job rotation, the use of storytelling, face-to-face conversations and job shadowing, only two of these mechanisms were selected with two $(13.3 \%)$ respondents reporting that mentorship programs were in use and six (40\%) indicated the use of job rotation for knowledge sharing. Despite the fact that the literature (Ramirez, 2007) showed that face-to-face or telephone conversations enable knowledge to be shared socially, the respondents did not select this option even if multiple responses were possible. Knowledge sharing as a social process requires that a space should be created to enable the interaction of employees. Organizational efforts should be focused on creating opportunities for employees to interact, whether formally or informally, to nurture knowledge sharing. The existence of a mentorship program demonstrates that there was a potential for employees to transfer subtle and private skills and experiences to others.

\section{Knowledge Sharing Processes}

Respondents were required to indicate the extent to which they viewed the listed statements on knowledge-sharing processes. Table 2 presents views from the respondents.

The responses revealed that there were no uniform processes of sharing knowledge among staff. A lack of formal knowledge-sharing processes is inimical to the optimum utilization of knowledge with negative results for service delivery.

There was also a question to the interviewees about the circulation of knowledge at TML where the researchers wanted to find out the extent to which knowledge was lost at TML. Particularly, the respondents were asked if any of either the retired employees or employees who resigned, were 
Table 2. Knowledge-sharing processes

\begin{tabular}{|c|c|c|c|c|c|}
\hline Statement & Agree & Strongly agree & Not sure & Disagree & Strongly disagree \\
\hline $\begin{array}{l}\text { Whenever new employees are hired at } \\
\text { TML, they are allocated a mentor. }\end{array}$ & $2(15.4 \%)$ & $2(15.4 \%)$ & $4(30.8 \%)$ & $1(7.7 \%)$ & $4(30.8 \%)$ \\
\hline $\begin{array}{l}\text { Has any of the employees who } \\
\text { resigned ever been recalled to assist } \\
\text { with library activities because no one } \\
\text { in the library knew how to do it? }\end{array}$ & $6(50 \%)$ & $2(16.7 \%)$ & $2(16.7 \%)$ & $2(16.7 \%)$ & - \\
\hline $\begin{array}{l}\text { Has any of the retired employees ever } \\
\text { been recalled to assist with library } \\
\text { activities because no one in the } \\
\text { library knew how to do it? }\end{array}$ & $5(41.7 \%)$ & $4(33.3 \%)$ & $1(8.3 \%)$ & $2(16.7 \%)$ & - \\
\hline $\begin{array}{l}\text { You belong to a formal grouping in } \\
\text { the library where you share work } \\
\text {-related activities. }\end{array}$ & $6(42.9 \%)$ & $5(35.7 \%$ & $2(14.3 \%)$ & $1(7.1 \%)$ & - \\
\hline $\begin{array}{l}\text { TML librarians are usually rotated } \\
\text { in various department such as } \\
\text { cataloguing, technical services and } \\
\text { others. }\end{array}$ & $6(46.2 \%)$ & $4(30.8 \%)$ & $2(15.4 \%)$ & $1(7.7 \%)$ & - \\
\hline $\begin{array}{l}\text { Librarians at TML share knowledge } \\
\text { by way of blogging. }\end{array}$ & $1(8.3 \%)$ & $4(33.3 \%)$ & $3(25 \%)$ & $4(33.3 \%)$ & - \\
\hline $\begin{array}{l}\text { Librarians at TML share knowledge } \\
\text { by way of Facebook. }\end{array}$ & $2(14.3)$ & $5(35.7 \%)$ & $3(21.4 \%)$ & $4(28.6 \%)$ & - \\
\hline
\end{tabular}

recalled to assist the library because their knowledge had not been captured when they left. All the interviewees answered in the affirmative. The fact that the interviewees felt their colleagues who resigned were not interviewed is very disturbing as they may have left with valuable knowledge that they acquired during their stay at TML. The following responses demonstrate that organizations should have processes of capturing the knowledge of those who would be leaving the organization.

Respondent 1: Right now as we speak, there is someone who has been recalled to come and assist I am not sure with what and in fact this is the second time that she is being recalled. The first time she was called she was even assigned mentees in order to transfer that knowledge to them. So it would seem to me that the skill was not transferred.

Respondent 2: Currently we have someone who is recalled. Unfortunately, this is the second time she is called because we had incidences of deaths in the library of people she mentored so she had to be recalled. Also during the University restructuring excise, we lost a number of skilled personnel through voluntary resignations and their departure was not effectively planned in terms of skills transfer.

Having knowledge-sharing processes has the potential of facilitating the optimal use and application of knowledge in an organization and improving service delivery to the clientele.

\section{Critical Success Factors of Knowledge Sharing}

The critical success factors of knowledge sharing are those factors that make it easy for people to share their knowledge in an organization. In that regard, the respondents were asked if the organizational structure of TML allows for ease of knowledge sharing. A total of six (40\%) respondents agreed with the statement that their organizational structure facilitated knowledge sharing, with one (6.7\%) respondent agreeing strongly. While four $(26.7 \%)$ respondents were not sure, two (13.3\%) disagreed 
and two (13.3\%) strongly disagreed with the statement. Tagliaventi and Mattarelli (2006) stated that knowledge sharing may be facilitated by having a less centralized organizational structure. Although TML was fairly centralized, it was small in size. The size of the organization provided a fertile ground for knowledge sharing. Organizational demographics, particularly large size and formal status differentials have a negative influence on knowledge sharing (Ramirez, 2007; Wang \& Noe, 2010). This implies that staff at TML have an opportunity to share knowledge by virtue of their size and that may make them efficient and help them deliver good services.

With regard to the provision of incentives, respondents held different views on whether or not incentives to share knowledge were provided at TML. For instance, four (26.7\%) of the respondents agreed that the incentives for knowledge sharing existed. The second group of three (20\%) respondents disagreed and an additional three (20\%) strongly disagreed. However, one (6.7\%) respondent indicated that they agreed with the statement, one was not sure, and three (20\%) remained mute. The reviewed literature suggested that the absence of incentives is directly linked to knowledge hoarding (Arzi, Rabanifard, Nassajtarshizi, \& Omran, 2013). Incentives, including recognition and rewards, have been suggested as interventions to ease knowledge sharing and help build a supportive culture (Islam, Ahmed, Hasan, and Ahmed, 2011, Arzi, Rabanifard, Nassajtarshizi, \& Omran, 2013).

\section{Knowledge-Sharing Obstacles}

The respondents were finally requested to indicate which of the provided knowledge-sharing obstacles applied to their library and multiple responses were possible. Table 3 presents the results.

Table 3. Obstacles to knowledge sharing

\begin{tabular}{|l|l|}
\hline Obstacles & Number of respondents \\
\hline "Knowledge is power" mentality & 4 \\
\hline Age difference & 3 \\
\hline Difference in experience & 3 \\
\hline Difference in qualifications & 4 \\
\hline Lack of trust & 6 \\
\hline Lack of rewards & 1 \\
\hline Lack of participation & 4 \\
\hline Other & 2 \\
\hline
\end{tabular}

It is clear that the respondents held different views on the obstacles to knowledge sharing. A lack of trust among employees was the greatest obstacle to knowledge sharing highlighted by six (40\%) respondents. The second greatest obstacle to knowledge sharing as held by four $(26.7 \%)$ respondents was a lack of participation and differences in qualifications. Another four (26.7\%) respondents believed that the "knowledge is power" mentality also hindered knowledge sharing. Age difference and differences in qualifications were viewed as obstacles to knowledge sharing at TML by three (20\%) respondents. One respondent pointed out a lack of rewards as an obstacle to knowledge sharing. The other two respondents selected the category "other" and were of the opinion that the mentees had a negative attitude towards their mentors and that TML staff seem to be selfish.

As can be noted from the statistics above, the majority of respondents held the view that trust seems to be a major obstacle of knowledge sharing at TML. These findings are, therefore, in agreement with, for example, Ngulube (2005) and Zenk, Hynek, Edelmann, Virkar, Parycek and Steiner (2021) 
who postulated that as a result of a lack of trust among employees there may be hostility to knowledge sharing in an organization. Riege (2005) also pointed to a number of other knowledge-sharing obstacles, which were also in agreement with the findings of this study, among which are differences in experience levels, age differences and differences in education levels, and a lack of trust in people because they may misuse knowledge or take unjust credit for it.

A significant number of respondents also held the view that the "knowledge is power" adage hindered knowledge sharing. This is in line with the suggestion made by Ramirez (2007) that the "knowledge is power" struggle creates inherent tensions between workers and the organization for which they work over who owns and controls their knowledge. This tension stems from the idea that knowledge is a resource with a significant amount of possible status and power and results in turf wars (Ramirez, 2007).

Organizations should strive to reduce obstacles to knowledge sharing so that the employees may operate efficiently and improve services to the clientele.

\section{CONCLUSION}

Knowledge sharing in academic libraries may result in improved services and innovativeness in fulfilling their mandate. This study provides empirical evidence on knowledge sharing at an academic library, which contributes to the growing knowledge on knowledge sharing and its role in supporting service delivery. In summary, this study intended to find out if knowledge sharing can be used as a tool to improve service delivery in the National University of Lesotho Library. In line with the objectives of this study, it is concluded that although knowledge sharing is not formalized at TML, it is considered important to service delivery. TML staff did not use technology-based tools for knowledge sharing, although some of the tools exist. Regarding the human-based knowledge-sharing mechanisms, the results of the study showed that only job rotation and mentorship programs were in use. Other human-based knowledge-sharing tools such as CoPs, job shadowing and storytelling did not exit. Furthermore, it was apparent from the study results that the library did not have a system for managing knowledge-sharing processes. The results indicated a lack of trust among colleagues and their difference in qualifications were some of the obstacles to knowledge sharing, including the "knowledge is power mentality" and a lack of rewards. This case study has implications for understanding knowledge sharing in support of service delivery in a library context. A theory on the phenomenon may be developed if more case studies are conducted to understand knowledge sharing and its role in service delivery. 


\section{REFERENCES}

Alawamleh, H. S., \& Kloub, M. A. (2013). Impact of organizational structure on knowledge management in the Jordanian insurance companies: From the perspective of the supervisory leadership. International Journal of Business and Social Science, 4(11), 82-96.

AlShamsi, O., \& Ajmal, M. (2018). Critical factors for knowledge sharing in technology-intensive organizations: Evidence from UAE service sector. Journal of Knowledge Management, 22(2), 384-412. doi:10.1108/JKM05-2017-0181

Andeniran, P. (2011). User satisfaction with academic libraries services: Academic staff and student perspectives. International Journal of Library and Information Science, 3(10), 209-216.

Arzi, S., Rabanifard, N., Nassajtarshizi, S., \& Omran, N. (2013). Relationship among reward system, knowledge sharing and innovation performance. Interdisciplinary Journal of Contemporary Research in Business, 5(6), 1-27.

Asogwa, B. (2012). Knowledge management in academic libraries: Librarians in the 21st century. Journal of Knowledge Management Practice, 13(2), 1-11.

Averweg, U. R. (2008). Developing an intranet towards knowledge sharing: A practitioner-based inquiry. South African Journal of Information Management, 10(1), 1-13. doi:10.4102/sajim.v10i1.7

Bhojaraju, G. (2005). Knowledge management: Why do we need it for corporate? Malaysian Journal of Library and Information Science, 10(2), 37-50.

Brčić, Z. J. \& Mihelič, K.K. (2015). Knowledge sharing between different generations of employees: an example from Slovenia. Economic Research-Ekonomska Istraživanja, 28(1), 853-867.

Burnette, M. (2017). Tacit knowledge sharing among library colleagues: A pilot study. RSR. Reference Services Review, 4(3), 382-397. doi:10.1108/RSR-11-2016-0082

Castaneda, D.I. \& Toulson, P. (2021). Is it possible to share tacit knowledge using information and communication technology tools? Global Knowledge, Memory and Communication, 1-11.

Christensen, P.H. (2007). Knowledge sharing: moving away from the obsession with best practices. Journal of Knowledge Management, 11(1), 36:47.

Colon-Aguirre, M. (2015). Knowledge transferred through organizational stories: A typology. Library Management, 36(6/7), 421-433. doi:10.1108/LM-06-2014-0073

Daland, H. (2016). Managing knowledge in academic libraries are we? Should we? LIBER Quarterly, 26(1), 28-41. doi:10.18352/lq.10154

Davenport, T. H., De Long, D. W., \& Beers, M. C. (1998). Successful knowledge management projects. Retrieved May 13, 2014, from https://sloanreview.mit.edu

Davenport, T. H., \& Prusak, L. (1997). Working knowledge: how organizations manage what they know. Harvard Business School Press.

Dube, L., \& Ngulube, P. (2012). Knowledge sharing in a multicultural environment: Challenges and opportunities. South African Journal of Library and Information Science, 78(1), 68-77. doi:10.7553/78-1-48

Gerbin, A., \& Drnovsek, M. (2020). Knowledge-sharing restrictions in the life sciences: Personal and contextspecific factors in academia-industry knowledge transfer. Journal of Knowledge Management, 24(7), $1533-1557$. doi:10.1108/JKM-11-2019-0651

Hosseini, E., \& Hashempour, L. (2012). The status of librarians' knowledge sharing by the usage of web 2.0 tools: A case study of central libraries of Tabriz governmental universities. Retrieved April 9, 2014, from http:// by2012.bilgiyonetimi.net/proceedings/hosseini_hashempour.pdf

Hundie, K. (2001). Retrospective conversion of card catalogue at the National University of Lesotho Library. African Journal of Library Archives and Information Science, 11(2), 149-157.

Islam, M. Z., Ahmed, S. M., Hasan, I., \& Ahmed, S. U. (2011). Organizational culture and knowledge sharing: Empirical evidence from service organizations. African Journal of Business Management, 5(14), 5900-5909. 
Jain, P. (2013). Knowledge management in academic libraries and information centres: A case of University libraries. Journal of Information \& Knowledge Management, 12(4), 1-13. doi:10.1142/S0219649213500342

Jantz, R. (2001). Knowledge management in academic libraries: Special tools and processes to support information professionals. Journal of Reference Service Review, 29(1), 33-39. doi:10.1108/00907320110366778

Jeung, C. W., Yoon, H. J., \& Choi, M. (2017). Exploring the affective mechanism linking perceived organizational support and knowledge sharing intention: A moderated mediation model. Journal of Knowledge Management, 21(4), 946-960. doi:10.1108/JKM-12-2016-0530

Kamal, K. J., Manjit, S. S., \& Gurvinder, K. S. (2007). Knowledge sharing among academic staff: a case study of business schools in Klang Valley, Malaysia. Retrieved July, 18, 2014, from https:/www.ucsi.edu.my/cervie/ ijasa/volume2/pdf/08A.pdf

Kim, J. (2015). Integrating communities of practice into library services. Collabora, 7(2), 47-55.

Lekhawipat, W., Wei, Y., \& Lin, C. (2018). How internal attributions affect knowledge sharing behavior. Journal of Knowledge Management, 22(4), 867-886. doi:10.1108/JKM-02-2017-0081

Malhotra, Y. (2000). Knowledge management, knowledge organizations and knowledge worker: a review from the frontlines. Retrieved January 6, 2014, from www.brint.com/interview/maeil.htm

Malinski, R. M. (2002). Job rotation in an academic library: Damned if you do and damned if you don't. Library Trends, 50(4), 673-680.

Maponya, P. (2004). Knowledge management practices in academic libraries: a case study of the University of Natal, Pietermaritzburg libraries. Retrieved September 12, 2013, from http://mapule276883.pbworks.com/f/ Knowledge+management+practices+in+academic+libraries.pdf

Marouf, L. (2017). Are academic libraries ready for knowledge management? The Electronic Library, 35(1), 137-151. doi:10.1108/EL-01-2016-0008

Mat Nor, N., Mat Khairi, S. M., Rosnan, H., Maskun, R., \& Johar, E. R. (2020). Establishing a knowledge-based organisation: Lesson learnt and KM challenges in Malaysian organisation. Innovation \& Management Review, 17(3), 235-249. doi:10.1108/INMR-05-2019-0065

Mavodza, J., \& Ngulube, P. (2011). Exploring the use of knowledge management practices in an academic library in a changing information environment. South African Journal of Library and Information Science, 77(1), 15-25. doi:10.7553/77-1-63

McDermott, R., \& O’Dell, C. (2001). Overcoming culture barriers to sharing knowledge. Journal of Knowledge Management, 5(1), 76-85. doi:10.1108/13673270110384428

Ngulube, P. (2005). Improving the quality of research outputs in higher education through knowledge sharing and collaboration: A case study. Mousaion, 23(1), 39-61.

Oyemomi, O., Liu, S., \& Neaga, I. (2015). The contribution of knowledge sharing to organizational performance: an integrative knowledge framework for sharing performance organizational decision making. Retrieved January 28, 2019, from, www.researchgate.net

Rahman, M. S., Mannan, M., Hossain, M. A., Zaman, M. H., \& Hassan, H. (2018). Tacit knowledge-sharing behavior among the academic staff: Trust, self-efficacy, motivation and big five personality traits embedded model. International Journal of Educational Management, 32(5), 761-778. doi:10.1108/IJEM-08-2017-0193

Rajurkur, M. (2011). Knowledge management in academic libraries. International Journal of Parallel and Distributed System, 2(11), 321-323.

Ramirez, A. (2007). To blog or not blog: Understanding and overcoming the challenge of knowledge sharing. Journal of Knowledge Management Practice, 8(1), 1-17.

Rao, K. (2018). Application of knowledge management in libraries. Retrieved January, 28 ${ }^{\text {th }}, 2019$, from, https:// www.researchgate.net

Riege, A. (2005). Three-dozen knowledge-sharing barriers managers must consider. Journal of Knowledge Management, 9(3), 18-35. doi:10.1108/13673270510602746 
Sanford, S., Schwartz, B., \& Khan, Y. (2020). The role of tacit knowledge in communication and decisionmaking during emerging public health incidents. International Journal of Disaster Risk Reduction, 50, 1-8. doi:10.1016/j.ijdrr.2020.101681 PMID:32834974

Shanhong, T. (2000). Knowledge management in libraries in the 21st century. Paper presented at the 66th IFLA Council and General Conference, Jerusalem, Israel. Retrieved January 5, 2014, from http://ifla.inist.fr/IV/ifla66/ papers/057-110e.htm

Smith, H. A., \& McKeen, J. D. (2009). Instilling a knowledge sharing culture. Retrieved September 11, 2013, from http://apollon1.alba.edu.gr/oklc2002/proceedings/pdf_files/id25.pdf

Ta, C. V., \& Zyngier, S. (2018). Knowledge sharing barriers in Vietnamese higher education institutions (HEIS). International Journal of Knowledge Management, 14(1), 51-69. doi:10.4018/IJKM.2018010104

Tagliaventi, M. R., \& Mattarelli, E. (2006). The role of networks of practice, value sharing and operational proximity in knowledge flows between professional groups. Journal of Human Relations, 59(3), 291-319. doi: $10.1177 / 0018726706064175$

Tan Nya Ling, C. (2011). Culture and trust in fostering knowledge. Electronic Journal of Knowledge Management, 9(4), 328-339.

Todorova, N., \& Mills, A. M. (2018). Why do people share? A study of intrinsic and extrinsic motivation to share knowledge in organisations. International Journal of Knowledge Management, 14(3), 1-20. doi:10.4018/ IJKM.2018070101

Wang, S., \& Noe, R. A. (2010). Knowledge sharing: A review and directions for future research. Human Resource Management Review, 20(4), 115-131. doi:10.1016/j.hrmr.2009.10.001

Wen, S. (2005). Implementing knowledge management in academic libraries: a pragmatic approach. Retrieved March 12, 2015, from https://www.whiteclouds.com/iclc/cliej/cl19wen.htm

Zenk, L., Hynek, N., Edelmann, N., Virkar, S., Parycek, P., \& Steiner, G. (2021). Exploring motivation to engage in intraorganizational knowledge sharing: A mixed-methods approach. Kybernetes, 1-28.

Tšeole Emmanuel Tahleho is a System Librarian at National University of Lesotho in Lesotho. His research interest is in knowledge management.

Patrick Ngulube, PhD, is a professor of information science and interdisciplinary research at the University of South Africa. His research interests as in records and archives, e-government, application of information and communication technologies, research methods and knowledge management, including indigenous knowledge systems. 